\title{
MIGRATION DIFFERENTIALS AMONG NIGERIAN PROFESSIONALS
}

Joseph UYANGA

\section{Introduction}

According to the free market model of population mobility, differences in the reward structure operate to draw workers from less rewarding to more rewarding work activities and places; changes in this structure are therefore likely to affect occupational and geographical mobility.

During the 1970s Nigeria experienced a tremendous economic expansion owing to the oil boom. This led to accelerated demand for professionals throughout the economy. During the same period the creation of more states spread economic activities throughout the country and effected the relocation of professionals. Studies have documented the fact that professionals earn more than other groups of workers in Nigeria. But what perhaps has not yet been adequately studied is the geographic movement of these professionals in response to changing economic conditions. For instance, how extensive has been their movement from the public to the private sector, or between States? What factors explain the differentials among various professional groups? Which are characterized by long-distance movement and which are not?

This paper attempts to answer these questions. As a scarce human resource, professionals must be optimally distributed among the various geographical regions in the country, if we are to meet the objectives of balanced development.

In a study of migration among professionals, Galle and Taeuber (1966) observe that various immigration rates have not been sufficiently desegregated with regard to important socio-economic variables. In other words, migration data do not seem to be systematically interpreted in terms of the most relevant structural factors such as 
occupations, work settings, and career patterns. It is not enough, for instance, to indicate that inter-State professional labour mobility in Nigeria is generally low. For that information to become meaningful to policy makers, the causes of immobility, among other things, must be desegregated into major occupational/professional categories. This paper attempts to do that.

The paper breaks down migration data into various occupations, distinguishing between professionals and non-professionals. The various classes of professionals are identified, followed by an analysis of the common structural conditions of work and career patterns that might explain variations in migration patterns and levels.

\section{The Professional}

Who is a professional? Apart from the fact that professionals are not a homogenous group, further definitional complexities are introduced by Carr-Saunders (1955) and by Reiss (1955). For instance, Reiss distinguishes the "old and established profession" (fine arts, architecture, law, missionary work); the "new profession' (pharmacy, teaching, engineering); the "semi-professions" or those who utilize precise technical skills rather than theoretical knowledge (editing, nursing, auditing, etc.); and the "marginal professions" or those that grow out of the need to apply technical skills in science and industry (medical technicians, surveyors, etc.).

However, this paper is not concerned with polemics over the classification of professionals, but rather with those professions on which there is national and international consensus. Among these are medicine, accountancy, law, architecture, engineering, surveying, and pharmacy.

\section{Hypotheses}

Several studies of inter-state migration have related mobility to a host of demographic, economic, and social characteristics, yet there is substantial evidence that not all the findings, that have emerged are equally applicable to the labour market for professionals. For example, Rees (1969) has reported in his study of the Chicago labour market that 
informal methods of finding jobs - such as referrals from employees or gate applications, which account for over four-fifths of all white-collar labour - account for only an insignificant proportion of professional workers.

The following generalizations are examined in this article:

1. That inter-State mobility rates are highest among the best educated, and, in occupational terms, higher among professionals than among general administrative/managerial workers.

2. That since there is an imbalance in the geographic (inter-State) distribution of the limited number of professionals in Nigeria, a higher mobility rate is expected (other things being equal) from those States with relatively greater supplies of scarce professional manpower than from the relatively disadvantaged States.

3. There is a considerable degree of job attachment among professionals, as reflected in low overall occupational mobility.

4. Salaried professionals have a higher inter-State mobility rate than do self-employed professionals. Similarly, salaried professionals have a higher rate of long-distance migration than do self-employed professionals.

5. Many of the professionals who migrate over long distances are characterized by strong collegiality and active nationwide occupation contact networks.

\section{Data}

This paper is based on data derived from a sample survey of high level manpower in Nigeria that was carried out between June and December of 1988. Six of the existing nineteen States were selected, to reflect not only the various levels of development but also a geographical balance between North and South. The States selected were Lagos, Kano, Bendel, Cross River, Plateau and Sokoto. Each State was broken down into public and private sectors. 
Within the public sector, the education and health subsectors were chosen. From these the officers designated senior staff were selected and respondents were randomly interviewed. In the private sector, a random sample of industries was chosen and staff in management positions were selected and interviewed. In all, 1365 staff were interviewed, out of which 513 were classified as professionals and kindred workers, excluding teachers.

For this analysis, the respondents were classified as either movers or non-movers. Movers are those residing in a state different from their State or origin, while the non-movers are those residing in the State of their origin. On-movers are again classified into those coming from contiguous States (short-distance migrants) and those coming from non-contiguous States.

\section{Limitation of the Sampling Procedure}

This approach, we recognize, is far from perfect. Relating the State of origin to the State of residence at the time of interview as a measure of mobility for example, fails to take account of workers who have worked in other States but have returned to their State of origin perhaps in preparation for retirement or as a result of pressure to return home after the creation of new States. To control for this bias we included a question on lifetime migration.

The survey permitted the collection of information on all types of job movements and allowed these to be thoroughly explored. Furthermore, the conditions that induced workers not to change geographic job location were also analyzed. Many of the early studies on mobility sutficied from the fact that they were limited to workers in specific local labour markets and were not desegregated by occupational category. This study has attempted to rectify that weakness.

\section{Characteristics of Nigerian Professionals}

More than 77 per cent of the sampled professionals were males, mostly in middle age. Table 1 shows that those surveyed were concentrated in the 30-40 age bracket, and that slightly more were 
found in the above-30 age bracket than in the below-30 age bracket. Most of them were married, as would be expected considering their advanced age. Separation and divorce rates were higher among them than for other occupational groups such as administration and management. Not surprisingly, the professionals were found to be highly educated, second only to teachers. Of the 881 respondents who held at least a university degree or its equivalent, 270 (31 per cent) were professionals, while 393 ( 44.6 per cent) were teachers (Table 2). The high level of education reported for teachers should not be a surprise inasmuch as our sample included university teachers, most of whom would normally hold at least one advanced degree. Besides supporting the claim that professionals constitute one of the most highly educated classes in the society, our findings also associated professionals with higher earning levels. Table 3 shows that professionals earned more than other categories of high and intermediate level manpower. About 37 per cent of the respondents who earned between N5,001 and N10,000 were professionals. This was closely followed by teachers, who accounted for about 31 per cent. The domination of the high income bracket by professionals became quite obvious when we examined those earning more than N10,000 per annum. Here professionals accounted for about 57 per cent, followed by those in the administrative group with 28.7 per cent; of the 21 respondents reporting earnings of N20,000 and above, 67.8 per cent were professionals. Another important finding was the existence of geographic wage differentials. Professionals in Lagos, for example, earned more than professionals in Kano, and indeed more than in all other State capitals. The explanation for this, as will be made clearer subsequently in this paper, was probably that most of the self-employed professionals were concentrated in Lagos, which is not only the Federal capital but also the nation's major commercial centre. Compared with Lagos, other State capitals were also dominated by professionals whose earnings were significantly higher than those of the other occupational categories.

\section{Mobility and Education}

We wished to know which occupational groups showed high and which showed low inter-State mobility in order to determine what general attributes of work and career might explain the differences. In 
general, mobility rates were highest among the best educated (as explained above). Inter-State mobility rose with additional years of post-primary education. It reached a peak with levels of education that can be categorized as intermediate and declined thereafter. It was highest among those categories of workers possessing Ordinary National Diploma (OND), Higher National Diploma (HND), the Nigerian Certificate of Education (NCE), and other intermediate manpower categories.

It is difficult to explain this phenomenon particularly since most of the States suffered from acute shortages in this category of manpower. Perhaps the only plausible reason was that the movement has been accentuated as a basis for ensuring upward occupational mobility. When these people moved they moved to occupy positions of greater responsibility, positions which they normally would not have assumed had they remained in the previous State of employment. This result was supported by the fact that majority of those who migrated to other States were relatively young and inexperienced. Over 35 per cent of those working in other States have worked for between one and five years and only 15 per cent have worked in these States for 20 years and over.

\section{Mobility and Occupation}

Mobility rates were lowest for professional workers. This is not surprising judging from the parabolic curve of the mobility rate by education. The professionals happened to find themselves at the upper range of higher education, where the mobility rate are expected to be lower than the rates for intermediate level education. However, our finding lower rates of mobility among professionals was at variance with the finding of several earlier reports. Thus Lansin and Mueller (1967) asserted: "The extent of geographic mobility varies among occupational groups. Migration rates are highest among the best educated and in occupational terms among professional and technical workers".

High mobility rates among professionals have been documented in Britain as well as in the United States. In the latter, for example, mobility among professionals has been found to be much higher than 
among any other group of workers. This apparently high mobility rate has been ascribed to the incidence of geographically mobile young workers entering the professional labour force.

From our data, only 58.8 per cent of the professionals were mobile while about 43 per cent of the professionals were not mobile. At the same time, 64 per cent and 60 per cent of the Administrative/Managerial and Secretarial/Executive occupational groups, respectively, were mobile. The possible explanation of the relatively rather low mobility found among professionals is the relatively recent emergence of most professions and the very high demand for existing professionals. Since professionals are relatively better remunerated and since they are needed in every State of the Federation, a professional does not need to make an inter-State move to improve his or her economic position. This is even more the case in view of the fact that inter-State moves are not without social, economic, and psychic costs.

This explanation conforms with the proposition that the people with the greatest incentive to engage in inter-State migration will be those with greatest prospects for considerably improving their economic positions. Consequently, those workers who are relatively worse off would have greater incentives to migrate. As we have said earlier, the junior and the intermediate workers, because of their perceived poverty, are likely to have greater desire to migrate to other States in a bid to improve their socioeconomic position. Conversely, the relatively comfortable status of professionals will hinder them from such movement. In addition, the non-economic benefits which professionals enjoy in their own States are usually more than sufficient to compensate for the difference in absolute income derivable from moving to other States and hence retard the movement of significant numbers. Factors such as social status, ownership of property, and the opportunity to participate in local politics all operate to reduce the incentives for inter-State mobility. 


\section{South-North Mobility of Professionals}

We had expected that there would be greater south-to-north mobility among professional and technical workers than north-to-south movement. This hypothesis was based on the fact that the southern States have a greater supply of professionals. Since the northern States have relatively more acute shortages of professional manpower, professionals would be able to attract higher salaries and better conditions of service in addition to higher probable occupational mobility.

Our survey produced some startling results, however. First, of the 513 Nigerian professionals interviewed, 138 (27 per cent) were Northerners, while the rest were Southerners. In general, professionals working in each of the two geographic regions came from that region. Specifically, most of the professionals practising in the northern States came from those States. Of the 203 professionals working in the three sampled northern States - Kano, Plateau and Sokoto - 136 (67 per cent) were from one or another of those three States, suggesting that only about one-third of all professionals in the North had migrated from the southern States.

The North-South mobility rate among Northern professionals was far lower still. Of the total of 282 professionals interviewed in the three southern States - Lagos, Bendel and Rivers - only two came from the North. It is as if the pattern of mobility of professionals reflected a definite preference for certain States. In terms of the political objective of reflecting Federal character, Plateau State and Kano State appear most representative. It is particularly significant to note that Lagos, despite the fact that it is the Federal capital, is not as representative as one would expect.

The situation is even worse in Cross River and Bendel States, where the influence of Northern professionals was least felt. In term of economic rationalization however, there is little justification for expecting many northern professionals in Lagos or Calabar. As we have observed earlier, the demand for professionals is even stronger at the State level where upward mobility is faster. When this is added to possible social problems in Lagos, the long term balance of economic 
benefits for northern professionals is higher in the North than in the South.

Our study also reported a high rate of inter-State labour mobility among States in a particular region. Thus of the 58 sampled non-state professionals working in Kano State, 23 (about 40 per cent) were from other northern States. The pattern is equally true for Plateau and Lagos States. We observed a significant effect of contiguity (nearness) on inter-State mobility of professionals. Several additional reasons both economic and non-economic - could be advanced for the relatively low North-South mobility among northern professionals. Most northern professionals secure more lucrative jobs in the North than they could secure in the South. Also, northerners are more strongly attached to their traditional society than are southerners. This feeling is reinforced by the perceived hostile environment in the South. All these factors significantly retard their movement to the southern States.

\section{Mobile Versus Immobile Professionals}

Our study showed structural differences among several occupations within the professional groupings. We observed for example, that salaried professionals have a higher migration rate than self-employed professionals. Salaried professions include those professions whose practitioners cannot easily establish their own private practice such as teachers (including university teachers, paramedical workers, and clergymen). On the other hand, those professions heavily characterized by self-employment recorded the lowest inter-State mobility rate. These included dentists, architects, and lawyers. The importance of the distinction between salaried and self-employed professionals is clearly illustrated by Table 5, which shows that the migration rate for salaried professional occupations is about twice that of self-employed professionals. A probable major reason for the lower migration rate for self-employed professionals is that as entrepreneurs they are tied down by heavy capital investments and by clienteles built up over many years. The most obvious cases are doctors, dentists, and lawyers. 
Salaried professionals, on the other hand, have relatively little capital outlay (or none at all) and are not so closely bound to clients. Professors and film stars, for example, have in common the fact that both can shift frequently and often hold "captive" rather than cultivated audiences. Judges and airplane pilots are similar in that their respective "clients" are transients who require no fiduciary relationships. Pharmacists and medical doctors are perhaps not as exceptional as they appear. The organization of the two professions often weakens the impact of salaried status through private practice. The salaried ones generally work hand in hand with self-employed superiors in relatively small clinics and stores, with the hope of building up clienteles and capital so as to shift to self-employed status. In short, they conform to a general proposition that professions that demand costly equipment purchase and close cultivation of clienteles block inter-State migration: once necessary equipment is purchased and extensive clienteles established it is difficult to move.

We also found that professionals with high rates of inter-State migration typically work in medium or small bureaucratic organizations with simple hierarchies and low manager-to-employee ratios. Professionals such as clergymen and intermediate technicians fall into this category. They tend to work in organizations with relatively few career stages and level of advancement within the organization. For most of these people, there are not many posts at the top to which they could advance. Career advancement usually comes about by changing organizations. Because of high demand for their skills and the national dispersion of relevant work organizations, job changes invariably involve geographic mobility. Consequently, for numerous salaried professionals as against self-employed professionals, a combination of highly marketable skills, blunted organizational advancement and decentralized work units fosters high rates of inter-State mobility.

\section{Short Versus Long Distance Movement}

Mobility distance for both salaried and self-employed professionals was also investigated. In general, salaried professionals were found to have higher long-distance mobility rates than did selfemployed professionals. For example, professors had higher long- 
distance rates than did lawyers, architects, or doctors. However, further investigation suggests other attributes of work that appear to facilitate this observed higher rate. Professionals with high longdistance migration rates are characterized by work conditions and salaries that vary widely from job to job and from one geographic area to another.

Professionals with very low long-distance mobility rates, such as dentist, pharmacists, and lawyers, are all characterized by relatively similar work conditions. One such common characteristics is that it is easy for them to become self-employed. An additional factor relates to the individual State's licensing requirements. The relative ease with which professionals can register and practise varies from State to State, and the difficulties of getting offices and housing for staff - and indeed that of obtaining the required staff - also retard movement to a considerable extent. Finally, those professionals who do not require approval from State governments to practise are in general more mobile than those that do require such approval.

One other occupational characteristic that one should mention is the close relationship between long-distance movement and strong professional contact. We found that the professional associations that are characterized by very strong collegiality have strong nation-wide organizations, such as the Nigerian Medical Association, the Nigerian Society of Registered Engineers, and the Nigerian Bar Association. Members of these professional associations are in close professional contact with each other. They organize regular professional conferences and meetings, and members read the associations' publications very closely. These professionals are constantly surrounded by wide-ranging occupational-based relationships and are thus quickly informed of job opportunities elsewhere.

\section{Conclusions and Policy Implications}

This article, which aims at adding to our understanding of interState labour mobility in Nigeria, has drawn attention to the following issues: 
a) The degree to which a person has heavy investment in capital equipment, clienteles and customers such that he cannot move or is reluctant to move.

b) The existence of strong professional groupings reflected in formal and informal occupational communication networks and their effect on inter-State mobility.

c) The extent to which work content and conditions, income and licensing are standardized throughout the States.

d) The relative availability of occupational career paths within organizations and occupations; and finally,

e) The relative demand for workers and the marketability of occupational skills.

Our analysis suggests, then, that most migratory professionals are not self-employed, nor are they the employees of large organizations. Career profile in large business firms appear to generate less inter-State migration than in smaller organization since more avenues for upward mobility exist in the larger organizations. This finding is in consonance with the conclusion that job mobility and migration are checked where there is movement through many career stages and organization levels within firms.

Professionals do move across States but particularly between States that are geographically close. While professionals from southern States migrate to and work in northern States, there appears to be a general unwillingness to move southward on the part of northern professionals. We also found that self-employed professionals were less mobile than salaried professionals. This suggests that the extent of capital investment and the importance of clients do have significant influence on inter-State mobility among professional workers.

The policy implication arising from this study is that if past performance is anything to go by, each State will be expected in the future to produce its own professional manpower. The prospect of relying on a supply of scarce skilled manpower from other States does not appear very bright because of the observed restricted mobility. In terms of labour market theory, therefore, it appears that there is a conflict between the theoretical labour market propositions and the actual labour market behaviour. In theory, there is a national labour 
market for professionals, but in practice, the market has been localized in that most Nigerian professionals look first for employment within their States of origin.

This phenomenon can be explained in terms of a supply analysis. Existing professionals easily find suitable jobs in their State of origin where future prospects and advancement are also surer. In the future, to the extent that labour markets for professionals becomes more saturated, particularly at the local level, we can expect that professionals will need to cross local labour market boundaries in search of employment opportunities. Under present conditions, however, short and medium term solutions lie in each State investing handsomely in manpower training and development within its own geographical area.

\section{Acknowledgement}

The data on which this paper is based is derived from Aderinto (1982). His acceptance is gratefully acknowledged. 


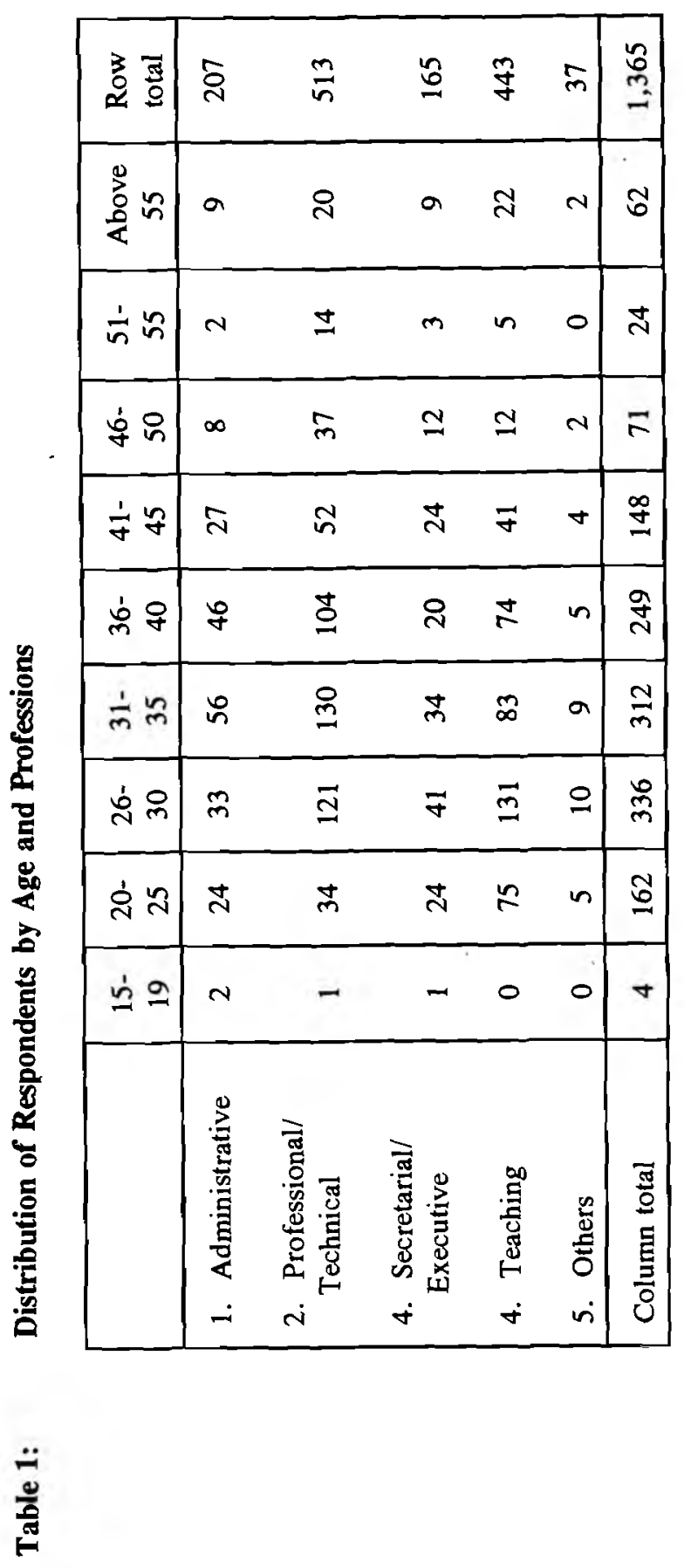




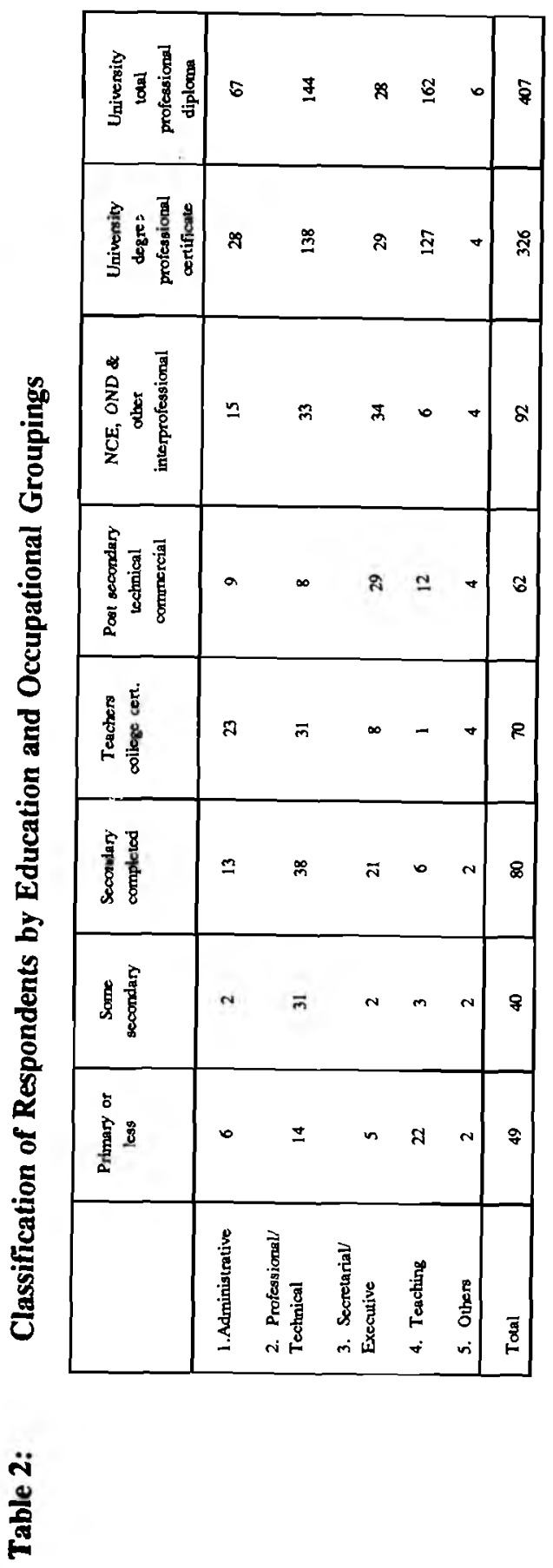




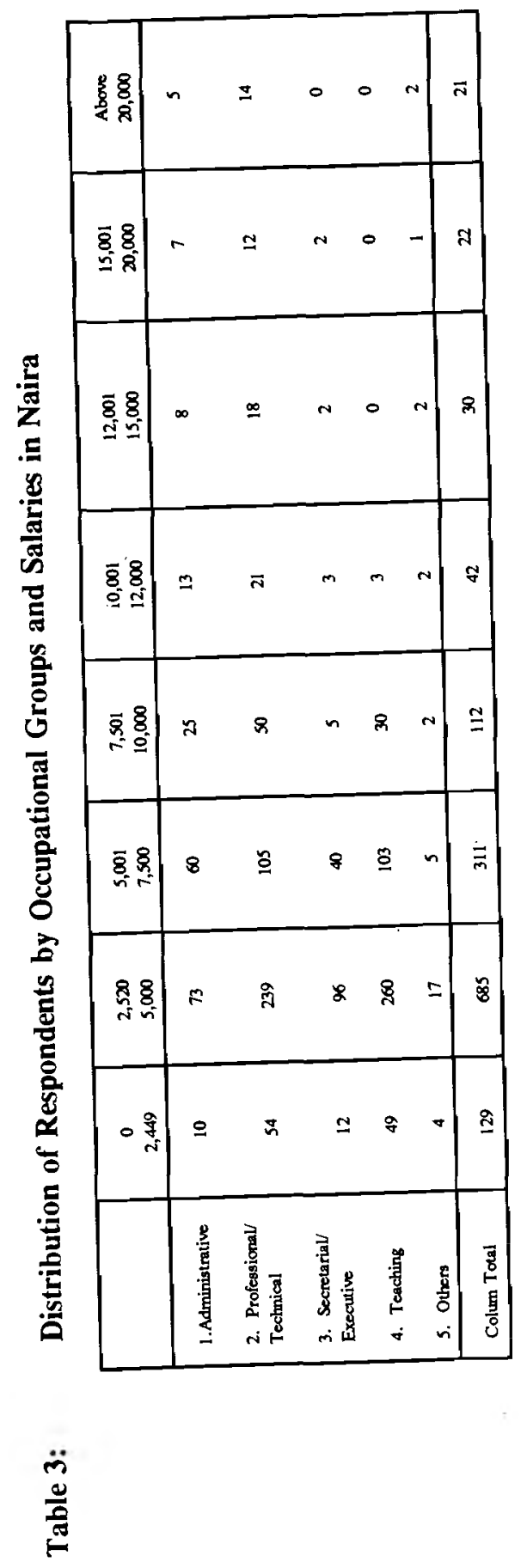



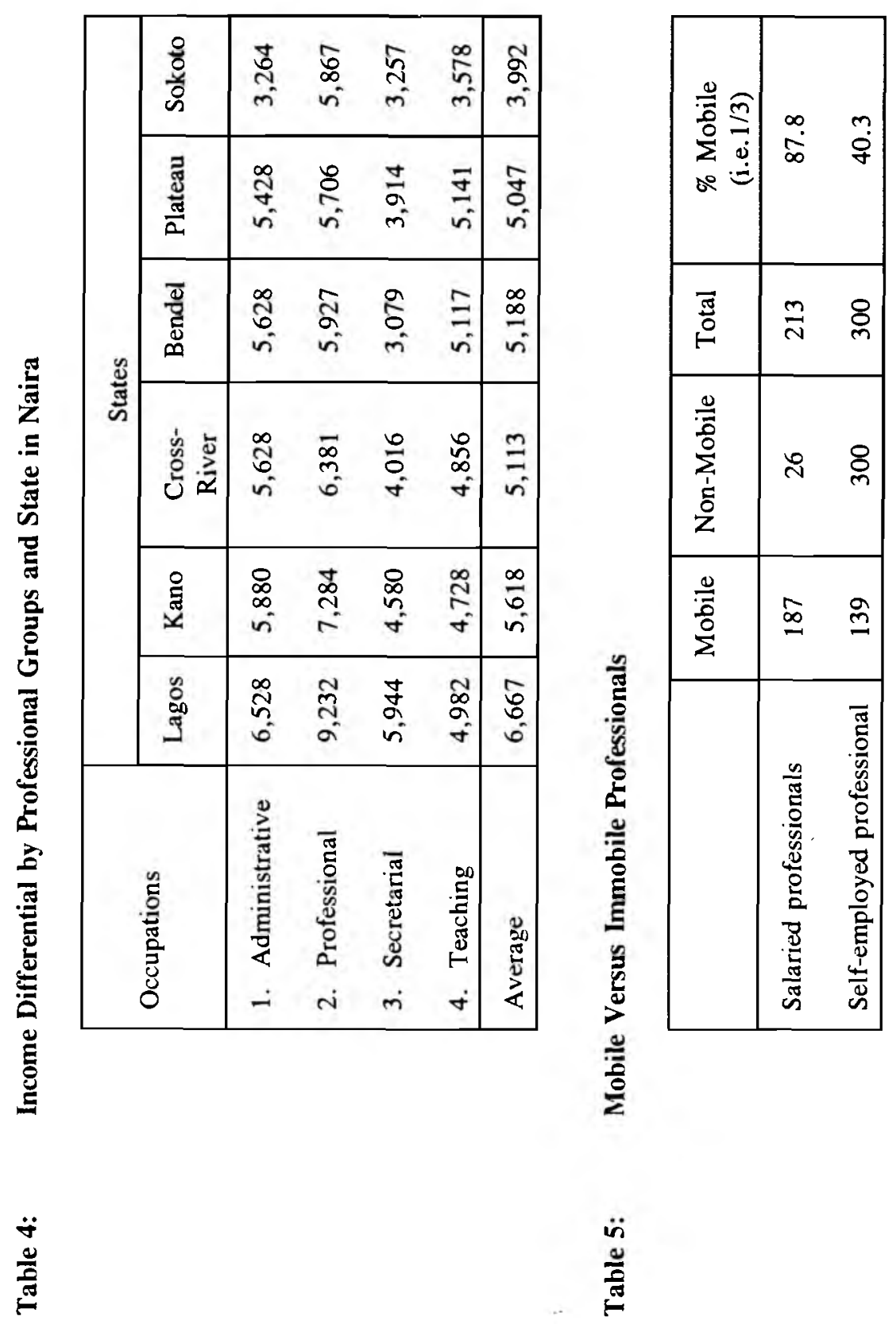


\section{Bibliography}

Aderinto, A. (1982). "Internal Labour Mobility and Economic Opportunities," Manpower Journal 16(4).

Batchelder, A.B. (1965). "Occupational and Geographic Mobility: Two Ohio Area Case Studies, "Industrial and Labour Relations Review 1.

Burton, R.B. (1961). "A Test of the Theory of Geographic Mobility," Industrial and Labour Relations Review 15.

Carr-Saunders, A. (1955). "Metropolitan Conditions and Traditional Relationship." In Robert Fisher, ed., The Metropolis in Modern Life. Garden City, N.Y.

Federal Republic of Nigeria (1975). The Public Service Review Panel Main Report. Lagos: Federal Ministry of Information.

Galle, A.R. and Taeuber, K.E. (1966). "Metropolitan Migration and Interviewing Opportunities," American Sociological Review 231.

Gitelman, H.M. (1966). "Occupational Mobility within Firms," Industrial and Labour Relations Review (October).

Greenberg, D. and Macal, J. (1974). "Teacher Mobility and Allocation," Journal of Human Resources 9(44).

Holen, A.S. (1965). "Effects of Professional Licensing Arrangements on Inter-state Labour Mobility and Resource Allocation," Journal of Political Economy 73.

Karz, F.E. (1958). "Occupational Contact Network," Social Forces 37.

Lane, J.H. and Donald, D.S. (1951). "Inter-state Migration Among College Graduates," Journal of Higher Education 22. 
Landinsky, J. (1976). Sources of Geographic Mobility Among Professional Workers, A Multi-Variate Analysis," Demography 14(1).

Lansin, J. B. and Mauller, E. (1967). The Geographic Mobility of Labour. Ann Arbor: University of Michigan Institute of Social Research.

Raimon, R.L. (1967). Inter-state Migration and Wage Theory," Review of Economics and Statistics 44.

Rees, A. (1969). "Information Networks in Labour Markets," American Economic Review Papers and Proceedings.

Reiss, J.A. (1955). "Occupational Mobility of Professional Workers," American Sociological Review 20.

Taver, J.D. (1964). "Occupational Migration Differential," Social Forces 45.

Thomas, D.S. (1958). "Age and Economic Differentials in Inter-state Migration", Population Index 24.

Uyanga, J. (1981). "African Mobility: A Source Paper," International Migration Review, 15:707-736.

Uyanga, J. (1981). "The Nature and Concepts of Migration Studies." Chapter 6 in Mandal, R.B., ed., Frontiers in Migration Analysis. New Delhi: Concept Publishers.

Uyanga, J. (1981). "An Alternative Opportunity Approach to Migration Analysis." Chapter 5 in Mandal, R.B., ed., Frontiers in Migration Analysis. New Delhi: Concept Publishers. 